\title{
INHIBITION EFFECT OF POLYURETHANE FOAM WASTE IN DIOXIN
}

FORMATION

Ana Isabel Moreno, Rafael Font, M. Francisca Gomez-Rico

4

Department of Chemical Engineering, University of Alicante, P.O. Box 99, E-03080

5

Alicante

6 * Corresponding author. Tel. + 34965903400 - ext. 2082; Fax Nr. + 34965903826.

7 E-mail address: paqui.gomez@ua.es (M. Francisca Gomez-Rico)

\section{Abstract}

9 The present work has been focused on studying the polychlorinated polychlorodibenzo-

$10 p$-dioxin/furan $(\mathrm{PCDD} / \mathrm{F})$ inhibition in the combustion process by prior addition of an

11 inhibitor to the fuel. Three different experiments of combustion were carried out at 850

${ }^{\circ} \mathrm{C}$ in a laboratory-scale horizontal tubular quartz reactor, and several compounds were analyzed from the flue gas obtained, such as PCDD/Fs, dioxin-like polychlorinated biphenyls (dl-PCBs), $\mathrm{NH}_{3}, \mathrm{HCN}, \mathrm{NO}_{\mathrm{x}}, \mathrm{HCl}, \mathrm{Cl}_{2}$, chlorobenzenes (ClBzs), chlorophenols (ClPhs), polycyclic aromatic hydrocarbons (PAHs), volatile and other semivolatile organic compounds. The fuel used was a synthetic waste which was composed of sawdust and PVC (95 wt $\%$ and $5 \mathrm{wt} \%$, respectively) and the inhibitors studied were polyurethane foam (PUF) that can be found in mattress waste and gases from the oxidative pyrolysis of PUF. Due to the high N content of PUF, a significant decrease of PCDD/F and dl-PCB formation has been obtained in the experimental runs carried out with the inhibitors studied, particularly with the gases from the oxidative pyrolysis of PUF. In addition, it must be noted that emissions of incomplete combustion products have also decreased. 


\section{Keywords}

24 Combustion, dioxins, inhibition, organic compounds, polyurethane

25 


\section{Introduction}

27 Waste incineration is a controversial topic due to unintentionally formation of toxic 28 polychlorodibenzo- $p$-dioxins/furans (PCDD/Fs) during the process. The emission of 29 PCDD/Fs can be high when incinerating chlorinated waste. For this reason, many studies

30 have been focused on the study of the mechanism of PCDD/F formation and technologies 31 to minimize their emission.

32 It is known that the possible pathways for PCDD/F formation during thermal processes 33 are: (i) some PCDD/F contained in the incoming feed could pass through due to an 34 incomplete destruction during combustion, (ii) reaction with dioxin precursors in the gas 35 phase at temperatures between 400 and $800{ }^{\circ} \mathrm{C}$, (iii) formation at low temperature (in the post-combustion zone between $200-400^{\circ} \mathrm{C}$ ) that involves: the de novo synthesis that uses

37 carbon and chlorine in fly ash to form PCDD/Fs or simultaneous oxidation and chlorination of aromatic hydrocarbons via catalytic-assisted by transition metal ions like $\mathrm{Cu}$ and $\mathrm{Fe}$ (Huang and Buekens, 1995). Pathway (i) has a rare occurrence in incinerators because combustion temperatures higher than $850^{\circ} \mathrm{C}$ and residence times higher than $2 \mathrm{~s}$

41 destroy all chlorinated organic molecules (Weber, 2007).

42 Due to the toxicity of these compounds, a large number of studies have been focused on possible methods to control PCDD/F emissions. Control techniques can be classified into two types, the first group of control techniques is focused on collecting and removing 45 these compounds from flue gases after their formation, which involves high investment and operating costs. The second group of control methods is focused on minimizing

$47 \mathrm{PCDD} / \mathrm{F}$ formation; therefore they seem to be the most economical and environmentally-

48 friendly control methods (Samaras et al., 2000). This group includes techniques like 
control of waste composition, pre-treatment for cleaning solid fuels, optimization of the combustion parameters and addition of inhibition compounds.

51 The most common additives for inhibition of $\mathrm{PCDD} / \mathrm{F}$ formation in thermal processes are

52 N- and S- containing compounds, and alkaline sorbents. Since the post-combustion zone

53 is the main critical point of the formation of PCDD/Fs, many researchers have carried out

54 experiments at the temperature range of post-combustion zone by impregnating model fly 55 ash with inhibitors or injecting the inhibitors into the flue gas (Fu et al., 2015; Hajizadeh 56 et al., 2012; Yan et al., 2014). However, adding organic compounds in the post57 combustion zone could result in an increase of CO emissions in the flue gases.

58 The possible mechanisms of inhibition with $\mathrm{N}$-containing compounds would be: i) 59 formation of stable metal nitride bonds, such us copper nitrides (Luna et al., 2000), thus blocking active sites of metals and reducing their catalytic activity (Hajizadeh et al., 2012), ii) reaction of the $\mathrm{N}$-additives and their degradation products with $\mathrm{PCDD} / \mathrm{F}$ precursors (Kuzuhara et al., 2005) or with the chlorine present in the post-combustion zone, avoiding the reaction of carbon and chlorine in fly ash to form PCDD/Fs (Zhan et al., 2016), iii) alteration of the acidity of fly ash, specially with $\mathrm{NH}_{3}$ due to their alkalinity, thereby losing aromatic chlorine by base-catalyzed elimination (Pandelova et al., 2005), iv) combustion of $\mathrm{N}$-containing compounds to form $\mathrm{NO}_{2}$, which is a stronger oxidant than

67 oxygen, favoring the oxidation of organic compounds and precursors (Marie-Rose et al., 68 2009).

69 Neither polyurethane foam (PUF) waste nor pyrolysis oxidative gas from PUF waste have been found in the literature as inhibitors of dioxin formation in the combustion of chlorinated compounds, although several N-containing compounds have demonstrated 
their inhibitor effect in the $\mathrm{PCDD} / \mathrm{F}$ formation and only few studies can be found regarding the use of waste with high $\mathrm{N}$ content as inhibitor. PUF is the main component of an important type of mattresses, which generates large amounts of bulky waste in

75 Europe and its main end is the landfill (Turner, 2014). PUF waste shows management problems, but its high $\mathrm{N}$ content could inhibit the $\mathrm{PCDD} / \mathrm{F}$ formation in thermal treatment of chlorinated waste, such as PVC cables, improving the management of both types of waste. No papers have been found about the study of PUF waste for this purpose as commented previously.

Another promising management treatment for biomass or polymer waste such as PUF is pyrolysis, which obtains energy and chemical products of high added value, solving also the issue of the large amount of waste generation. Regarding the chemical products obtained, recently, several researchers have focused on the production of carbonaceous nanoparticles (CNPs), due to their large number of applications in high value manufacturing technologies (Dubey et al., 2014; Jander et al., 2019; Maroufi et al., 2017; Santhiago et al., 2018; Tripathi et al., 2014). However, the production of CNPs is limited and expensive at the moment. Nevertheless, pyrolysis of fuel with significant nitrogen content such as PUF produces gaseous $\mathrm{NH}_{3}$ at high levels (Garrido et al., 2016; Moreno and Font, 2015), which has been found as an effective inhibitor of the PCDD/F formation (Hajizadeh et al., 2012; Liu et al., 2015; Ruokojärvi et al., 2004). In addition, it must be noted that the first stage of combustion is a pyrolysis process, in which $\mathrm{NH}_{3}$ formation can be high if the nitrogen content of the fuel is significant. Therefore, $\mathrm{NH}_{3}$ produced in combustion of PUF or in a previous pyrolysis (oxidative pyrolysis) can act as inhibitor as commented previously. 
This work aimed for the study of PCDD/F inhibition by prior addition of N-containing compounds to a model waste (a mixture of sawdust and PVC) in a laboratory reactor, in order to control properly the operating conditions. Other compounds were also analyzed to study the effect of PCDD/F inhibitors on other pollutants evolved in the combustion process. The inhibitors studied were PUF and gases from the oxidative pyrolysis of PUF.

100 The mentioned model waste was selected to assure that a considerable amount of 101 chlorinated compounds could be evolved.

\section{Experimental section}

\subsection{Characteristics of materials and experimental procedure}

104 The materials employed for the combustion runs were: PUF from mattress waste, which was collected from a Municipal Solid Waste Treatment Plant, sawdust from wood, which was supplied by Energías Renovables Tarazona S.A. (Albacete, Spain), and PVC resin Etinox-450. Major elements (C, H, N, S) of the PVC resin were analyzed by a Leco Micro TuSpec Elemental Analyzer and the characterization of PUF and sawdust and the methods used were presented in previous works (Conesa and Soler, 2017; Garrido et al., 2016). For comparison purposes, the results are shown in Table 1 . The high $\mathrm{N}$ content of PUF is noteworthy since its nitrogen degradation products could act as inhibitors of

$112 \mathrm{PCDD} / \mathrm{F}$ formation in thermal processes. On the other hand, the $\mathrm{Cl}$ content in PVC is also

113 remarkable. A synthetic waste was obtained with sawdust and PVC (95 wt\% and 5 wt\%,

114 respectively), so a model waste with high $\mathrm{Cl}$ content could lead to a high $\mathrm{PCDD} / \mathrm{F}$ 115 formation during combustion. 
117 The experiments of combustion were carried out at $850^{\circ} \mathrm{C}$ in a laboratory-scale horizontal 118 tubular quartz reactor previously described in detail by Font et al (2003). A small amount 119 of sample (around $60 \mathrm{mg}$ ) is introduced inside a reactor with controlled temperature, and 120 in the latter part of the reactor some quartz raschig rings are placed, which promote the 121 secondary cracking reactions. Synthetic air (79\% nitrogen, $21 \%$ oxygen) was used in the 122 experiments. These set-ups were carried out under substoichiometric conditions (ratio $123 \mathrm{CO} /\left(\mathrm{CO}+\mathrm{CO}_{2}\right)$ around 0.1$)$ to promote the formation of incomplete combustion products. The outlet gas was passed through a Tedlar bag or XAD-2 resin to collect the compounds of interest for their analysis.

126 In each experiment, the exact amount of each material was added to the crucible used in 127 the reactor, in order to assure the composition of the feeding material. The mixture of the 128 different materials was carried out manually with a glass rod to obtain a uniform feeding.

129 Three different experiments were carried out with the synthetic waste as fuel: M0, M1 130 and M2. The M0 experiment was carried out without inhibitors in order to observe the $131 \mathrm{PCDD} / \mathrm{F}$ levels during combustion of the synthetic waste used and to compare the effect of the inhibitors afterwards. The M1 experiment studied the effect of the first inhibitor, the addition of $5 \mathrm{wt} \%$ of PUF to the synthetic waste. This percentage was selected taking 134 into account the results of Fu et. al (2015), who observed a PCDD/F decrease of $97.7 \%$ 135 by adding inhibitors to ash with a molar ratio $(\mathrm{N}+\mathrm{S}) / \mathrm{Cl} 0.47$, or 0.19 as weight ratio. In the $\mathrm{M} 1$ experiment, the $\mathrm{N} / \mathrm{Cl}$ weight ratio in the mixture was 0.11 in order to observe the inhibition effect with an intermediate ratio. The M2 experiment studied the effect of the second inhibitor, the addition of gases from the oxidative pyrolysis of PUF to the inlet gas, containing $\mathrm{NH}_{3}$ and other $\mathrm{N}$ - compounds which can act as inhibitors of the PCDD/F

140 formation. In order to obtain these gases from oxidative pyrolysis of PUF, a previous 
141 experiment of thermal decomposition of PUF was carried out in the same reactor at 850

$142{ }^{\circ} \mathrm{C}$, obtaining a mixture of gases with 1.8 vol\% of $\mathrm{O}_{2}$. These gases obtained were mixed

143 with air for the M2 combustion runs, at a ratio of approximately $24 \%$ of oxidative 144 pyrolysis gases and $76 \%$ of air. The flowrate was $225 \mathrm{~mL} / \mathrm{min}\left(25^{\circ} \mathrm{C}\right.$ and $\left.1 \mathrm{~atm}\right)$ for the $145 \mathrm{M} 0$ and M1 experiments (solids + air) ad $300 \mathrm{~mL} / \mathrm{min}\left(25^{\circ} \mathrm{C}\right.$ and 1 atm) for the M2 146 experiment (solids + gas mixture with pyrolysis gas). The duration was 4 min for the M0

147 and M1 experiments and 3 min for the M2 experiment, to assure that the sample was 148 totally burned and the compounds evolved were collected correctly. The residence time 149 was $3.5 \mathrm{~s}$ for the M0 experiments and M1 and $5 \mathrm{~s}$ for the M2 experiment.

150 Gases from oxidative pyrolysis of PUF used for the M2 experiment show high $\mathrm{NH}_{3}, \mathrm{HCN}$ 151 and nitrogen oxides content (Table 2), which were also found in previous works as 152 effective inhibitors of PCDD/F formation (Hajizadeh et al., 2012; Kuzuhara et al., 2005;

153 Marie-Rose et al., 2009). The variations of the composition correspond to the standard 154 deviation between analyses from 3 different oxidative pyrolysis runs. Since some of these compounds are hazardous, its presence in the latter combustion experiments was taken 156 into account.

Table 2

158 From the outlet gas obtained in the combustion experiments mentioned above, PCDD/Fs 159 and dl-PCBs (dioxin-like polychlorinated biphenyls) were analyzed, but also $\mathrm{Cl}_{2}$ and 160 other different compounds, such as $\mathrm{NH}_{3}, \mathrm{HCN}, \mathrm{NO}_{x}, \mathrm{HCl}$, volatile and semivolatile 161 organic compounds. Among the semivolatile organic compounds, PCDD/F precursors such as chlorobenzenes (ClBzs) and chlorophenols (ClPhs), as well as priority polycyclic aromatic hydrocarbons (PAHs), were specially taken into account. 
164 Additional information about the gases evolved in the combustion of these materials has

165 been obtained through thermogravimetric analysis (TG) coupled with both mass 166 spectrometer (MS) and Fourier-transform infrared (FTIR) spectrometer, in order to

167 corroborate the results obtained with the horizontal tubular quartz reactor.

168 The TG-MS analyses were carried out in a Mettler Toledo TGA/SDTA851e/LF/1600

169 (TG-DTA) with an alumina crucible in series with a Pfeiffer Vacuum Quadrupole Mass

170 Spectrometer (QMS) Thermostar GSD301T. The sample mass used was approximately 5

$171 \mathrm{mg}$. Runs were performed at a heating rate of $30^{\circ} \mathrm{C} / \mathrm{min}$ with a flow rate of $100 \mathrm{~mL} / \mathrm{min}$

172 of $\mathrm{He}: \mathrm{O}_{2}(4: 1)$. This atmosphere was selected in order to determine the evolution of $\mathrm{CO}$

173 avoiding the overlap of $\mathrm{m} / \mathrm{z}$ ions from $\mathrm{N}_{2}$. The response of the different ions was divided

174 by that of helium $(\mathrm{m} / \mathrm{z}=4)$ and subtracted from that corresponding to the beginning of

175 the run.

176 The TG-FTIR analyses were carried out in a TG STA6000 (PerkinElmer) with a ceramic

177 crucible at a heating rate of $50{ }^{\circ} \mathrm{C} / \mathrm{min}$ coupled to a Nicolet 6700 FTIR spectrometer.

178 Resolution in FTIR was set at $4 \mathrm{~cm}^{-1}$ and spectra were collected at 32 scans in the range

$179400-4000 \mathrm{~cm}^{-1}$. TGA measurements were performed using around $5 \mathrm{mg}$ of sample.

\subsection{Methodologies of analysis}

181 Triplicate combustion experiments were carried out for the analyses of $\mathrm{NH}_{3}, \mathrm{HCN}, \mathrm{HCl}$,

$182 \mathrm{Cl}_{2}$, volatile compounds and organic semivolatile compounds, whereas analyses of

$183 \mathrm{PCDD} / \mathrm{Fs}$ and dl-PCBs were carried out in duplicate. In addition, blanks of the

184 experiments and the apparatus used were also carried out prior to the corresponding runs. 
185 Apart from their analysis in the combustion experiments, $\mathrm{NH}_{3}, \mathrm{HCN}, \mathrm{HCl}, \mathrm{Cl}_{2}$ and other 186 gases and volatile compounds were analyzed in the flue gas from the oxidative pyrolysis 187 of PUF.

188

189

190

191

192

193

194

195

196

197

198

199

200

201

202

203

204

205

206

2.2.1. Sampling and analysis of ammonia, hydrogen cyanide, hydrogen chloride and chlorine.

The U.S. EPA CTM 027 method was followed for sampling and analysis of ammonia emissions (EPA, 1997). This method consists of passing the evolved gases through two impingers containing a sulphuric acid solution $(0.1 \mathrm{~N})$ in order to retain the released ammonia. The amount of ammonium in the solution was analyzed by ion chromatography (Dionex DX500).

The U.S. EPA OTM 029 method was followed for sampling and analysis of hydrogen cyanide emissions (EPA, 2011). This method consists of passing the evolved gases through two impingers containing a $0.1 \mathrm{~N} \mathrm{NaOH}$ solution and $\mathrm{HCN}$ is trapped by the alkali solution as cyanide ion $\left(\mathrm{CN}^{-}\right)$. The amount of cyanide in the solution was analyzed by ion chromatography (Dionex DX500).

The U.S. EPA 051 method was followed for sampling of hydrogen chloride and chlorine emissions, by the use of impingers like in the previous cases. In acidified absorbing solutions, the $\mathrm{HCl}$ gas is solubilized and forms chloride ions $\left(\mathrm{Cl}^{-}\right)$. The acidified solution used was $0.1 \mathrm{~N}$ sulphuric acid solution. The $\mathrm{Cl}_{2}$ gas was sampled in alkaline absorbing solution (0.1N NaOH solution) (EPA, 1996a). The U.S. EPA 9057 method was followed for the determination of $\mathrm{HCl}$ and $\mathrm{Cl}_{2}$ by the analyses of obtained solutions by ion chromatography (Dionex DX500) (EPA, 1996b). 
208 Gases evolved were collected in Tedlar ${ }^{\circledR}$ bags. $\mathrm{O}_{2}, \mathrm{~N}_{2}, \mathrm{H}_{2}, \mathrm{CO}$ and $\mathrm{CO}_{2}$ were analyzed 209 in an Agilent 7890A Gas Chromatograph coupled to a Thermal Conductivity Detector 210 (GC-TCD) equipped with a first packed column (HayeSep Q) with 80/100 mesh and a 211 second packed column (MolSieve 5A) with 80/100 mesh. A Shimadzu GC-17A Gas 212 Chromatograph coupled to a Flame Ionization Detector (GC-FID) with a capillary 213 column Alumina $\mathrm{KCl}$ Plot was used to analyze the aliphatic hydrocarbons $\mathrm{C}_{1}-\mathrm{C}_{6}$ (with 214 low boiling points). In addition, for the analysis of other non-condensable organic 215 compounds, an Agilent 6890N Gas Chromatograph was used, coupled to an Agilent $2165973 \mathrm{~N}$ mass spectrometer (GC-MS) with a DB-624 capillary column (30 m x $0.25 \mathrm{~mm}$ x $217 \quad 1.4 \mu \mathrm{m})$

218 Tedlar ${ }^{\circledR}$ bags were also needed to collect the gases for the analyses of nitrogen oxides 219 (NO and $\mathrm{NO}_{2}$ ), which were carried out with a calibrated IM-2800 portable gas analyzer 220 (Environmental Equipment Germany GmbH).

\subsubsection{Sampling and analysis of organic semivolatile compounds.}

222 The gas stream passed through an adsorptive trap containing XAD-2 resin to retain PAHs,

223 ClBzs, ClPhs and other semivolatile compounds. Before extraction, internal standards

224 were added, specifically $5 \mu \mathrm{L}$ of deuterated PAH Mix 26 (Dr. Ehrenstorfer-Schäfers, 225 Augsburg, Germany), $10 \mu \mathrm{L}$ of $13 \mathrm{C}$-labelled $\mathrm{ClPh}$ and $10 \mu \mathrm{L}$ of $13 \mathrm{C}$-labelled $\mathrm{ClBz}$ 226 (Wellington Laboratories, Ontario, Canada). The resins were extracted with a mixture of 227 dichloromethane/acetone, using Accelerated Solvent Extraction, according to the U.S. 228 EPA method 3545A (EPA, 2007a). The extracts obtained were concentrated and finally 229 the recovery standard anthracene-d10 (AccuStandard, New Haven, USA) was spiked. 
230 The 16 priority PAHs and other semivolatile organic compounds were quantified 231 according to the U.S. EPA method 8270D (EPA, 2007b). Analyses of PAHs were carried 232 out in an Agilent 6890N Gas Chromatograph coupled to an Agilent 5973N Mass 233 Spectrometer (GC-MS) with a HP-5MS capillary column $(30 \mathrm{~m} \times 0.25 \mathrm{~mm} \times 0.25 \mu \mathrm{m})$

234 by the isotope dilution method. The identification of semivolatile compounds was done 235 by comparing unknown mass spectra with NIST database reference spectra and a 236 semiquantitative determination of the yield was calculated with the response factors of 237 the deuterated internal standard with the nearest retention time. The SIR mode was used 238 for the analyses of $\mathrm{ClPhs}$ and $\mathrm{ClBzs}$, confirming each isomer with the ratio between the 239 areas of the primary and secondary ions.

240 2.2.4. Sampling and analysis of PCDD/Fs and dioxin-like PCBs.

241 Samplings of PCDD/Fs and dl-PCBs were also carried out passing the flue gases through 242 an adsorptive trap containing XAD-2 resin. However, for analysis of PCDD/Fs and dl243 PCBs, between 6 and 20 consecutive combustions were carried out (being retained their 244 emissions by the same XAD-2 resin), in order to amplify the signal in the analysis.

245 The resin extractions and the following purification and clean-up of the extracts for the 246 simultaneous analyses of 2,3,7,8-substituted PCDD/Fs and 12 dioxin-like PCBs were 247 carried out according to a modification of the U.S. EPA Method 1613, taking into account 248 the U.S. EPA Method 1668 (Moltó et al., 2006).

249 The purified extracts were analyzed with a Thermo Finnigan MAT95 XP High250 Resolution Mass Spectrometer connected to a Thermo Finnigan Trace GC 2000 Gas 251 Chromatograph. A J\&W DB-5MS (60 m x $0.25 \mathrm{~mm} \times 0.1 \mu \mathrm{m})$ capillary column was used 
252 for PCDD/F determination and a DB-XLB (60 $\mathrm{m} \times 0.25 \mathrm{~mm} \times 0.25 \mu \mathrm{m})$ for dl-PCBs

253 determination.

254 3. Results and discussion

255 Table 3 shows the results corresponding to the formation of carbon oxides, nitrogen 256 oxides, $\mathrm{NH}_{3}, \mathrm{HCN}, \mathrm{HCl}$, chlorine and the main light hydrocarbons in $\mathrm{M} 0$ and $\mathrm{M} 1$

257 combustion runs. The results for the M2 experiment, however, are shown separately in 258 Table 4 since this was carried out with an addition of a percentage of gases from the 259 oxidative pyrolysis of PUF into the inlet gases (flow gas to carry out the combustion). 260 This gas introduces carbon oxides, nitrogen oxides, $\mathrm{NH}_{3}, \mathrm{HCN}$, etc. into the reactor. 261 Therefore, this different initial condition of the combustion experiment must be 262 considered in order to evaluate the results accurately. For this consideration, Table 4 263 shows the composition of the inlet gas, the composition of the outlet gas and the 264 difference between both of them. Inlet gas for M0 and M1 combustion runs basically 265 contains air, therefore it does not need to be analyzed in these experiments.

Table 3

Table 4

268 Comparing the inlet gas with the outlet one in the M2 combustion, Table 4 shows that obviously carbon oxides increase in flue gas due to the solid fuel combustion. Inlet gas shows a high content of light hydrocarbons, although these compounds were oxidized

271 during combustion, some of them were completely oxidized and the rest of them reduced 272 their yield significantly. Inlet gas for M2 combustion shows a significant content of $\mathrm{NH}_{3}$ 273 and $\mathrm{HCN}$, although these compounds were oxidized during the M2 run. Even though they 
274 were not completely consumed, their decrease was quite considerable (Table 4). In

275 addition, an increase of NO was observed in flue gases from M2 combustion compared

276 to the composition of its inlet gas. It is known that the oxidation of $\mathrm{NH}_{3}$ and $\mathrm{HCN}$

277 produces nitrogen oxides, which could explain their increase. Specifically, Marie-Rose et

278 al. (2009) explained that the ammonia adsorbed in the strong acid sites of particles reacts

279 with the oxygen that is also adsorbed and they form $\mathrm{NO}_{(\mathrm{g})}$ (Eq. 1) and $\mathrm{NO}$ formed is

280 quickly oxidized into $\mathrm{NO}_{2 \text { (g) }}$ (Eq. 2).

$281 \quad \mathrm{NH}_{3(\mathrm{a})}+\mathrm{O}_{(\mathrm{a})} \rightarrow \mathrm{NO}_{(\mathrm{g})}+\mathrm{H}_{2(\mathrm{~g})}+\mathrm{H}_{(\mathrm{a})}$

282

$\mathrm{NO}_{(\mathrm{g})}+\mathrm{O}_{(\mathrm{a})} \rightarrow \mathrm{NO}_{2(\mathrm{~g})}$

283 In addition, Glarborg and Miller (1994) proved that the main oxidation route for HCN

284 forms NCO (Eq. 3) and the products of the subsequent reactions of NCO depend on the 285 gas composition and temperature (Eqs. 4-7).

$286 \mathrm{HCN}+\mathrm{OH} \rightarrow \mathrm{CN}+\mathrm{H}_{2} \mathrm{O} \rightarrow \mathrm{NCO}+\mathrm{O}$

$287 \mathrm{NCO}+\mathrm{O} \rightarrow \mathrm{NO}+\mathrm{CO}$

$288 \mathrm{NCO}+\mathrm{O}_{2} \rightarrow \mathrm{NO}+\mathrm{CO}_{2}$

$289 \mathrm{NCO}+\mathrm{NO} \rightarrow \mathrm{N}_{2} \mathrm{O}+\mathrm{CO}$

$290 \mathrm{NCO}+\mathrm{NO} \rightarrow \mathrm{N}_{2}+\mathrm{CO}_{2}$

291 The previous equations could explain the great decrease in the emission factors of nitrogen compounds observed in Table 4 concerning the M2 experiment. Comparing the 
different combustion runs, according to Tables 3 and 4 the $\mathrm{CO} /\left(\mathrm{CO}+\mathrm{CO}_{2}\right)$ ratios are

294 slightly lower in the experiments carried out with inhibitors, but the three ratios are around

0.10. This indicates that the oxygen conditions for the three combustion processes were substoichometric and similar, what could occur at some points of a commercial waste incinerator.

Marie-Rose et al. (2009) suggested that the presence of $\mathrm{NH}_{3}$ seems to favor the formation of coke and also the decrease of the $\mathrm{CO}_{2}$ formation. At low temperature (ca. $300{ }^{\circ} \mathrm{C}$ ), $\mathrm{NH}_{3}$ adsorbs on the strong acid sites. Therefore, the oxidation of organic molecules into carbon dioxide is reduced, but the formation of PCDD/Fs could also be reduced due to the blocking of these strong acid sites. Concerning this matter, Tables 3 and 4 show that the lowest yield of $\mathrm{CO}_{2}$ corresponded to the $\mathrm{M} 2$ experiment, due to the significant ammonia content in the inlet gas of this experimental run.

The yield of $\mathrm{NO}_{\mathrm{x}}$ slightly increases in the experiments carried out with the inhibitor, but despite this increase, the $\mathrm{NO}_{\mathrm{x}}$ emissions obtained do not exceed the permitted limits of the Directive 2010/75/EU on industrial emissions for waste incineration plants (daily average emission limit: $200 \mathrm{mg} / \mathrm{Nm}^{3}$ of $\mathrm{NO}$ and $\mathrm{NO}_{2}$, expressed as $\mathrm{NO}_{2}$ ).

M1 experiment shows a higher $\mathrm{HCN}$ content in its flue gases comparing with the content obtained in flue gases of M0 experiment (Table 3). Flue gases from M2 experiment also

311 show a higher $\mathrm{NH}_{3}$ and $\mathrm{HCN}$ content, although it must be noted that inlet gas for this

312 experiment shows a significant $\mathrm{NH}_{3}$ and $\mathrm{HCN}$ content as mentioned before, which were

313 greatly oxidized during combustion run (Table 4).

314 It must be considered that combustions with excess oxygen consume the $\mathrm{HCN}$ and $\mathrm{NH}_{3}$ formed. Nevertheless, if there is not sufficient oxygen, a higher $\mathrm{N}$ content in the materials 
to burn (due to the inhibitor used) will produce a higher $\mathrm{HCN}$ and $\mathrm{NH}_{3}$ content in the flue

317 gases. It must be taken into account that these experiments were carried out under 318 substoichiometric conditions, therefore, $\mathrm{HCN}$ and $\mathrm{NH}_{3}$ emissions will be probably 319 negligible if combustions were carried out with excess oxygen.

320 It is also noteworthy that there are decreases in the yield of some main light hydrocarbons

321 in the experiments carried out with inhibitors.

322 Concerning $\mathrm{HCl}$ and $\mathrm{Cl}_{2}$ yields, the values obtained were relatively similar for $\mathrm{M} 0$ and

323 M1 experiments. However, a higher difference was observed in the flue gases obtained 324 in $\mathrm{M} 2$ experiment. The higher $\mathrm{Cl}_{2}$ content in flue gases from $\mathrm{M} 2$ combustion could be 325 due to the formation of $\mathrm{NO}$ (by $\mathrm{NH}_{3}$ and $\mathrm{HCN}$ ). Subsequently, this $\mathrm{NO}$ is quickly oxidized 326 into $\mathrm{NO}_{2}$ and the formed $\mathrm{NO}_{2}$ can react with $\mathrm{HCl}$ and produces $\mathrm{Cl}_{2}$ (Eq. 8) (favored 327 reaction).

329 Additional information about these combustion processes were obtained with TG-FTIR 330 and TG-MS analyses. The main results obtained from TG-FTIR and their discussions are

331 shown in Appendix A, and it can be concluded that combustion experiments carried out 332 with inhibitors produce lower yield of volatile organic compounds, which corroborates 333 the results obtained in the horizontal quartz tubular reactor.

334 Concerning TG-MS analysis, an interesting result obtained must be discussed. Fig. 1 335 shows the intensities of ions corresponding to $\mathrm{HCl}(\mathrm{m} / \mathrm{z}, 36)$ and $\mathrm{Cl}_{2}(\mathrm{~m} / \mathrm{z}, 70)$ from the 336 TG-MS runs for M0 and M1 combustions. It can be observed that the formation of $\mathrm{Cl}_{2}$ in 337 M0 combustion is negligible. This result is in agreement with that obtained in the 
338 laboratory-scale reactor (Table 3). On the other hand, TG-MS results show that the $\mathrm{Cl}_{2}$

339 formation increases and the $\mathrm{HCl}$ formation decreases for $\mathrm{M} 1$ combustion, comparing with

340 the results of M0 combustion. The addition of PUF with high nitrogen content to the fuel

341 is the reason of this result, as previously mentioned, since high nitrogen content in the

342 fuel can form a significant yield of $\mathrm{NO}_{2}$ and consequently, the formed $\mathrm{NO}_{2}$ can react with

$343 \mathrm{HCl}$ and produces $\mathrm{Cl}_{2}$.

\section{Figure 1}

345 Table 5 shows the emission factors of the PAHs obtained, the total yield of semivolatile

346 compounds and $\mathrm{ClBz}$ and $\mathrm{ClPh}$ yields. Emissions of the PAHs studied were also lower

347 in the experiments carried out with the inhibitors. Naphthalene, acenaphthylene,

348 phenanthrene and fluoranthene were the majority PAHs obtained in all cases.

349 Furthermore, other 51 semivolatile compounds were identified and quantified and they

350 are shown in Table B1 of Appendix B. Their total yields were also lower in M1 and M2

351 combustion experiments (with the inhibitors).

Table 5

353 Table 6 shows the PCDD/F and dl-PCB yields and the total toxicity equivalence (TEQ)

354 in the combustion runs. Values for TEQ were calculated using the toxicity equivalency

355 factor given by the World Health Organization (WHO) (Van den Berg et al., 2006).

Table 6

357 The results suggest that the addition of PUF to the model waste and the addition of the gases from the oxidative pyrolysis of PUF reduce PCDD/F and dl-PCB formation. 
359 Although the yield of $\mathrm{Cl}_{2}$ is the highest one in the $\mathrm{M} 2$ combustion experiment, $\mathrm{PCDD} / \mathrm{F}$

360 and dl-PCB formation is the lowest. The reason could be the low yield of organic products

361 of incomplete combustion obtained in the M2 combustion experiment (Tables 4 and 5).

362 From Table 6, it can be observed that the yields of toxicity equivalent of PCDFs are much

363 higher than that corresponding to PCDDs. This trend is mainly observed in M0

364 experiment (combustion of model waste) and this was also the tendency during the

365 combustion of PVC (Font et al., 2010).

366 Taking into account that yields of ClBzs and ClPhs are similar in the three runs, probably

367 the interaction of the $\mathrm{N}$-compounds takes place in the reactions of these precursors leading 368 to a formation of PCDD/Fs and dl-PCBs. By inhibiting the formation, ClBzs and ClPhs 369 do not react.

\section{Conclusions}

371 The addition of polyurethane foam to the model waste and the addition of the gases from

372 the oxidative pyrolysis of PUF inhibit PCDD/F and dl-PCB formation in combustion. The

373 first alternative reduces the formation of PCDD/Fs by $85.7 \%$ and dl-PCBs by $81.2 \%$ in 374 toxicity WHO-TEQ, and the second one $99.6 \%$ and $99.99 \%$ respectively. Both 375 alternatives are interesting, being the direct addition of PUF waste the simplest one. The 376 addition of gases from oxidative pyrolysis increases the inhibition potential.

377 Both addition of PUF and gases from its oxidative pyrolysis to the synthetic waste produce higher yield of $\mathrm{NH}_{3}, \mathrm{HCN}$ and $\mathrm{NO}_{\mathrm{x}}$ in thermal processes, but the presence of $\mathrm{NH}_{3}$ and $\mathrm{HCN}$ in the flue gases from combustion is easier to control than PCDD/Fs and dl-PCBs, and $\mathrm{NO}_{\mathrm{x}}$ levels do not surpass the emission limit. In addition, significant yield 
381 reductions of organic volatile and semivolatile compounds have been obtained in the

382 experiments carried out with the inhibitors studied. This is due to the presence of $\mathrm{NO}_{\mathrm{x}}$ in

383 these experiments, since $\mathrm{NO}_{2}$ is a stronger oxidant than oxygen and consequently reduces

384 products of incomplete combustion. In addition, the presence of $\mathrm{N}$-compounds and the

385 reduction of products of incomplete combustion can also cause a decrease of PCDD/F

386 and dl-PCB formation.

387 The proposed alternatives could help to avoid the PCDD/F and dl-PCB formation during

388 incineration of waste with a high $\mathrm{Cl}$ content such as PVC cables, and at the same time

389 they allow the treatment of bulky waste such as used mattresses.

\section{Acknowledgments}

391 Support for this work was provided by the Spanish Ministerio de Economia y

392 Competividad, Research Project CTQ2016-76608-R (Spain).

\section{References}

394 Conesa, J.A., Soler, A., 2017. Decomposition kinetics of materials combining biomass 395 and electronic waste. J Therm Anal Calorim 128, 225-233.

396 Dubey, P., Tripathi, K.M., Sonkar, S.K., 2014. Gram scale synthesis of green fluorescent 397 water-soluble onion-like carbon nanoparticles from camphor and polystyrene foam. RSC 398 Advances 4, 5838-5844.

399 EPA, 1996a. Method 0051. Midget impinger HCl/Cl2 emission sampling train., United 400 States Environmental Protection Agency, Washington, DC. 
EPA, 1996b. Method 9057. Determination of chloride from $\mathrm{HCl} / \mathrm{Cl} 2$ emission sampling

402 train (methods 0050 and 0051) by anion chromatography., United States Environmental

403 Protection Agency, Washington, DC.

404 EPA, 1997. Procedure for Collection and Analysis of Ammonia in Stationary Sources

405 (CTM-027). United States Environmental Protection Agency, Washington, DC.

406 EPA, 2007a. Method 3545A. Pressurized Fluid Extraction (PFE). United States

407 Environmental Protection Agency, Washington, DC.

EPA, 2007b. Method 8270D. Semivolatile Organic Compounds by GC/MS., United

409 States Environmental Protection Agency, Washington, DC.

410 EPA, 2011. OTM 29. Sampling and Analysis of Hydrogen Cyanide Emissions from

411 Stationary Sources, Other Test Method 29, United States Environmental Protection

412 Agency, Washington, DC.

413 Font, R., Aracil, I., Fullana, A., Martín-Gullón, I., Conesa, J.A., 2003. Semivolatile 414 compounds in pyrolysis of polyethylene. Journal of Analytical and Applied Pyrolysis 68$41569,599-611$.

416 Font, R., Gálvez, A., Moltó, J., Fullana, A., Aracil, I., 2010. Formation of polychlorinated 417 compounds in the combustion of PVC with iron nanoparticles. Chemosphere 78, 152418159.

419 Fu, J.-Y., Li, X.-D., Chen, T., Lin, X.-Q., Buekens, A., Lu, S.-Y., Yan, J.-H., Cen, K.-F., 420 2015. PCDD/Fs' suppression by sulfur-amine/ammonium compounds. Chemosphere $421 \quad 123,9-16$. 
422 Garrido, M.A., Font, R., Conesa, J.A., 2016. Pollutant emissions during the pyrolysis and

423 combustion of flexible polyurethane foam. Waste Management 52, 138-146.

424 Glarborg, P., Miller, J.A., 1994. Mechanism and modeling of hydrogen cyanide oxidation 425 in a flow reactor. Combustion and Flame 99, 475-483.

426 Hajizadeh, Y., Onwudili, J.A., Williams, P.T., 2012. Effects of gaseous NH3 and SO2 on 427 the concentration profiles of PCDD/F in flyash under post-combustion zone conditions. 428 Waste Management 32, 1378-1386.

429 Huang, H., Buekens, A., 1995. On the mechanisms of dioxin formation in combustion 430 processes. Chemosphere 31, 4099-4117.

431 Jander, H., Borchers, C., Böhm, H., Emelianov, A., Schulz, C., 2019. Structure of 432 carbonaceous nanoparticles formed in various pyrolysis systems. Carbon.

433 Kuzuhara, S., Sato, H., Tsubouchi, N., Ohtsuka, Y., Kasai, E., 2005. Effect of Nitrogen434 Containing Compounds on Polychlorinated Dibenzo-p-dioxin/Dibenzofuran Formation 435 through de Novo Synthesis. Environmental Science \& Technology 39, 795-799.

436 Liu, X., Wang, J., Wang, X., Zhu, T., 2015. Simultaneous removal of PCDD/Fs and NOx 437 from the flue gas of a municipal solid waste incinerator with a pilot plant. Chemosphere $438133,90-96$.

439 Luna, A., Amekraz, B., Morizur, J.P., Tortajada, J., Mó, O., Yáñez, M., 2000. Reactions 440 of Urea with $\mathrm{Cu}+$ in the Gas Phase: An Experimental and Theoretical Study. The Journal 441 of Physical Chemistry A 104, 3132-3141. 
442 Marie-Rose, S.C., Belin, T., Mijoin, J., Fiani, E., Taralunga, M., Chaucherie, X., Nicol,

443 F., Magnoux, P., 2009. Destruction of PAH and dioxin precursors using selective

444 oxidation over zeolite catalysts. Influence of the presence of ammonia in the flue gas.

445 Applied Catalysis B: Environmental 93, 106-111.

446 Maroufi, S., Mayyas, M., Sahajwalla, V., 2017. Nano-carbons from waste tyre rubber:

447 An insight into structure and morphology. Waste Management 69, 110-116.

448 Moltó, J., Font, R., Conesa, J.A., 2006. Study of the Organic Compounds Produced in the 449 Pyrolysis and Combustion of Used Polyester Fabrics. Energy \& Fuels 20, 1951-1958.

450 Moreno, A.I., Font, R., 2015. Pyrolysis of furniture wood waste: Decomposition and 451 gases evolved. Journal of Analytical and Applied Pyrolysis 113, 464-473.

452 Pandelova, M.E., Lenoir, D., Kettrup, A., Schramm, K.-W., 2005. Primary Measures for 453 Reduction of PCDD/F in Co-Combustion of Lignite Coal and Waste: Effect of Various 454 Inhibitors. Environmental Science \& Technology 39, 3345-3350.

455 Ruokojärvi, P.H., Asikainen, A.H., Tuppurainen, K.A., Ruuskanen, J., 2004. Chemical 456 inhibition of PCDD/F formation in incineration processes. Science of The Total 457 Environment 325, 83-94.

458 Samaras, P., Blumenstock, M., Lenoir, D., Schramm, K.W., Kettrup, A., 2000. PCDD/F 459 prevention by novel inhibitors: Addition of inorganic S- and N-compounds in the fuel 460 before combustion. Environmental Science and Technology 34, 5092-5096. 
461 Santhiago, M., Garcia, P.S., Strauss, M., 2018. Bio-based nanostructured carbons toward 462 sustainable technologies. Current Opinion in Green and Sustainable Chemistry 12, 2246326.

464 Tripathi, K.M., Sonker, A.K., Sonkar, S.K., Sarkar, S., 2014. Pollutant soot of diesel 465 engine exhaust transformed to carbon dots for multicoloured imaging of E. coli and 466 sensing cholesterol. RSC Advances 4, 30100-30107.

467 Turner, J., 2014. Recycling special: Europe. European Bedding Industries' Association 468 Magazine, pp. 28-34.

469 Van den Berg, M., Birnbaum, L.S., Denison, M., De Vito, M., Farland, W., Feeley, M., 470 Fiedler, H., Hakansson, H., Hanberg, A., Haws, L., Rose, M., Safe, S., Schrenk, D., 471 Tohyama, C., Tritscher, A., Tuomisto, J., Tysklind, M., Walker, N., Peterson, R.E., 2006. 472 The 2005 World Health Organization reevaluation of human and mammalian toxic 473 equivalency factors for dioxins and dioxin-like compounds. Toxicological Sciences 93, $474 \quad 223-241$.

475 Weber, R., 2007. Relevance of PCDD/PCDF formation for the evaluation of POPs 476 destruction technologies - Review on current status and assessment gaps. Chemosphere 477 67, S109-S117.

478 Yan, M., Qi, Z., Yang, J., Li, X., Ren, J., Xu, Z., 2014. Effect of ammonium sulfate and 479 urea on PCDD/F formation from active carbon and possible mechanism of inhibition. 480 Journal of Environmental Sciences 26, 2277-2282. 
481 Zhan, M., Chen, T., Lin, X., Fu, J., Li, X., Yan, J., Buekens, A., 2016. Suppression of

482 dioxins after the post-combustion zone of MSWIs. Waste Management 54, 153-161.

483

484 
Table 1. Characterization of the materials used.

\begin{tabular}{ccccccc}
\hline $\begin{array}{c}\text { Analysis on } \\
\text { dry basis }\end{array}$ & $\mathbf{C}(\mathbf{w t} \%)$ & $\mathbf{H}(\mathbf{w t} \%)$ & $\mathbf{N}(\mathbf{w t} \%)$ & $\mathbf{S}(\mathbf{w t} \%)$ & $\mathbf{O}(\mathbf{w t} \%)$ & $\mathbf{C l}(\mathbf{w t} \%)$ \\
\hline Sawdust & 51.6 & 6.5 & $<0.01$ & $<0.01$ & 41.9 & 0.12 \\
PVC & 39.0 & 4.9 & $<0.01$ & $<0.01$ & $<0.01$ & 56.2 \\
PUF & 57.8 & 7.4 & 5.95 & 0.01 & 23.4 & 0.04 \\
\hline
\end{tabular}

486

487 
Table 2. Composition of the gases from the oxidative pyrolysis of PUF

\begin{tabular}{cc}
\hline \multicolumn{2}{c}{ PUF oxidative pyrolysis gases } \\
\hline $\mathrm{H}_{2}(\mathrm{vol} \%)$ & $12.5 \pm 0.5$ \\
$\mathrm{O}_{2}($ vol\%) & $1.8 \pm 0.8$ \\
$\mathrm{~N}_{2}(\mathrm{vol} \%)$ & $84.5 \pm 0.2$ \\
$\mathrm{CO}_{2}(\mathrm{vol} \%)$ & $0.21 \pm 0.01$ \\
$\mathrm{CO}(\mathrm{vol} \%)$ & $0.93 \pm 0.06$ \\
$\mathrm{NO}_{\mathrm{x}}(\mathrm{mg} / \mathrm{kg}$ PUF $)$ & $2430 \pm 260$ \\
$\mathrm{NH}_{3}(\mathrm{mg} / \mathrm{kg}$ PUF $)$ & $8650 \pm 1040$ \\
$\mathrm{HCN}(\mathrm{mg} / \mathrm{kg}$ PUF $)$ & $20610 \pm 1340$ \\
\hline
\end{tabular}

489

490 
runs.

\begin{tabular}{ccc}
\hline \multirow{2}{*}{ COMPOUND } & \multicolumn{2}{c}{ mg compound/kg dry solid fuel } \\
\cline { 2 - 3 } $\mathrm{CO}_{2}$ & $1607000 \pm 48000$ & $1655000 \pm 249000$ \\
$\mathrm{CO}$ & $200000 \pm 49000$ & $187000 \pm 21000$ \\
Ratio $\mathrm{CO} /(\mathrm{CO}+$ & $0.11 \pm 0.02$ & $0.10 \pm 0.01$ \\
$\left.\mathrm{CO}_{2}\right)$ & $480 \pm 20$ & $920 \pm 110$ \\
$\mathrm{NO}$ & $480 \pm 80$ & $170 \pm 180$ \\
$\mathrm{NO}_{2}$ & $950 \pm 60$ & $1090 \pm 150$ \\
$\mathrm{NO}_{\mathrm{x}}$ & $4 \pm 2$ & $15 \pm 5$ \\
$\mathrm{NH}_{3}$ & $580 \pm 20$ & $1180 \pm 130$ \\
$\mathrm{HCN}$ & $8000 \pm 1800$ & $9040 \pm 2460$ \\
$\mathrm{HCl}$ & $200 \pm 40$ & $380 \pm 160$ \\
$\mathrm{Cl}{ }_{2}$ & $18400 \pm 1280$ & $14580 \pm 3370$ \\
Methane & $90 \pm 10$ & $20 \pm 10$ \\
Ethane & $1830 \pm 920$ & $460 \pm 150$ \\
Ethene & $2250 \pm 200$ & $20 \pm 40$ \\
Acetylene & $60 \pm 10$ & $\mathrm{nd}$ \\
1,3 -Butadiene & $5900 \pm 600$ & $1470 \pm 1040$ \\
Benzene & $210 \pm 200$ & $\mathrm{nd}$ \\
Toluene & & \\
& &
\end{tabular}

493

494 
Table 4. Composition of the inlet gas for M2 combustion (expressed as mass of added compounds per mass of dry solid fuel to be combusted), yield of the main gases evolved in M2 combustion and difference of the main gases between outlet and inlet yields.

\begin{tabular}{|c|c|c|c|}
\hline \multirow[b]{2}{*}{ COMPOUND } & \multicolumn{3}{|c|}{ mg compound/kg dry solid fuel } \\
\hline & $\begin{array}{l}\text { Inlet gas for } \mathrm{M} 2 \\
\text { combustion }\end{array}$ & $\begin{array}{l}\text { Outlet gas from M2 } \\
\text { combustion }\end{array}$ & $\begin{array}{c}\text { Difference } \\
\text { between outlet and } \\
\text { inlet yields }\end{array}$ \\
\hline $\mathrm{CO}_{2}$ & $39500 \pm 3000$ & $1385000 \pm 251000$ & $1346000 \pm 178000$ \\
\hline $\mathrm{CO}$ & $46600 \pm 4100$ & $131000 \pm 34000$ & $85000 \pm 24000$ \\
\hline $\begin{array}{c}\text { Ratio } \mathrm{CO} /(\mathrm{CO}+ \\
\left.\mathrm{CO}_{2}\right)\end{array}$ & $0.54 \pm 0.04$ & $0.09 \pm 0.02$ & \\
\hline NO & $490 \pm 230$ & $1230 \pm 410$ & $740 \pm 330$ \\
\hline $\mathrm{NO}_{2}$ & $<1$ & $<29$ & $<29$ \\
\hline $\mathrm{NO}_{\mathrm{x}}$ & $490 \pm 160$ & $1260 \pm 290$ & $770 \pm 240$ \\
\hline $\mathrm{NH}_{3}$ & $6200 \pm 2090$ & $2130 \pm 450$ & $-4060 \pm 1510$ \\
\hline $\mathrm{HCN}$ & $16430 \pm 1190$ & $1000 \pm 210$ & $-15430 \pm 850$ \\
\hline $\mathrm{HCl}$ & Negligible* & $7940 \pm 1630$ & $7940 \pm 1150$ \\
\hline $\mathrm{Cl}_{2}$ & Negligible* & $6650 \pm 4780$ & $6650 \pm 3380$ \\
\hline Methane & $126600 \pm 8500$ & $3800 \pm 100$ & $-122800 \pm 6000$ \\
\hline Ethane & $7280 \pm 440$ & $10 \pm 20$ & $-7270 \pm 310$ \\
\hline Ethene & $105300 \pm 6400$ & $440 \pm 330$ & $-104900 \pm 4500$ \\
\hline Propane & $500 \pm 80$ & nd & $-500 \pm 50$ \\
\hline Propene & $20600 \pm 1700$ & nd & $-20600 \pm 1200$ \\
\hline Acetylene & $9130 \pm 480$ & $170 \pm 100$ & $-8950 \pm 400$ \\
\hline n-Butane & $1400 \pm 110$ & nd & -1400 \\
\hline 1-Butene & $360 \pm 120$ & nd & $-360 \pm 90$ \\
\hline Isobutene & $280 \pm 60$ & nd & $-280 \pm 40$ \\
\hline Propyne & $1850 \pm 140$ & nd & $-1850 \pm 100$ \\
\hline 1,3-Butadiene & $9130 \pm 1110$ & $100 \pm 180$ & $-9030 \pm 790$ \\
\hline 1-Butyne & $3660 \pm 1110$ & nd & $-3660 \pm 790$ \\
\hline Benzene & $28100 \pm 600$ & $1500 \pm 170$ & $-26600 \pm 500$ \\
\hline Toluene & $6510 \pm 1160$ & $1310 \pm 460$ & $-5200 \pm 880$ \\
\hline
\end{tabular}


Table 5. 16 EPA priority PAHs, total semivolatile compounds, chlorobenzenes and

\begin{tabular}{|c|c|c|c|}
\hline \multirow[b]{2}{*}{ COMPOUND } & \multicolumn{3}{|c|}{ mg compound/kg dry sample } \\
\hline & $\begin{array}{c}\text { M0 (wood/PVC) } \\
(n=3)\end{array}$ & $\begin{array}{c}\text { M1 (wood/PVC/PUF }) \\
(\mathrm{n}=\mathbf{3})\end{array}$ & $\begin{array}{c}\text { M2 }(\text { wood/PVC/PUF } \\
\text { pyrolysis gases) }(n=3)\end{array}$ \\
\hline Naphthalene & $193.8 \pm 94.6$ & $67.8 \pm 26.0$ & $83.9 \pm 53.0$ \\
\hline Acenaphthylene & $99.1 \pm 66.6$ & $21.7 \pm 13.5$ & $26.0 \pm 19.6$ \\
\hline Acenaphthene & $0.4 \pm 0.4$ & nd & nd \\
\hline Fluorene & $1.0 \pm 0.5$ & nd & nd \\
\hline Phenanthrene & $134.5 \pm 79.8$ & $31.3 \pm 15.7$ & $26.2 \pm 19.6$ \\
\hline Anthracene & $14.5 \pm 7.4$ & $2.2 \pm 0.6$ & $1.6 \pm 1.2$ \\
\hline Fluoranthene & $43.1 \pm 29.7$ & $9.0 \pm 4.2$ & $8.5 \pm 7.6$ \\
\hline Pyrene & $28.6 \pm 13.0$ & $3.5 \pm 1.7$ & $6.0 \pm 5.4$ \\
\hline Benzo(a)anthracene & $8.9 \pm 5.1$ & $1.1 \pm 0.6$ & $0.3 \pm 0.1$ \\
\hline Chrysene & $22.6 \pm 10.8$ & $3.3 \pm 1.7$ & $1.1 \pm 0.3$ \\
\hline Benzo(b)fluoranthene & $9.1 \pm 3.1$ & $1.8 \pm 0.5$ & $2.6 \pm 1.7$ \\
\hline Benzo(k)fluoranthene & $4.4 \pm 1.6$ & $0.7 \pm 0.6$ & $0.9 \pm 0.7$ \\
\hline Benzo(a)pyrene & $4.0 \pm 1.4$ & $0.41 \pm 0.04$ & $0.6 \pm 0.5$ \\
\hline Indeno(1,2,3-cd)pyrene & $3.4 \pm 2.8$ & $0.04 \pm 0.07$ & $0.3 \pm 0.4$ \\
\hline Dibenz(a,h)anthracene & $0.4 \pm 0.5$ & nd & nd \\
\hline Benzo(g,h,i)perylene & $1.6 \pm 0.9$ & $0.06 \pm 0.06$ & $0.2 \pm 0.4$ \\
\hline Total 16 PAHs & 569.5 & 142.9 & 158.0 \\
\hline $\begin{array}{l}\text { Total semivolatile } \\
\text { compounds }\end{array}$ & 1156.3 & 443.3 & 480.6 \\
\hline \multicolumn{4}{|c|}{ Chlorobenzenes ( $\mu \mathrm{g} / \mathrm{kg}$ dry basis) } \\
\hline MONO- & $35900 \pm 8700$ & $15400 \pm 5700$ & $27700 \pm 8700$ \\
\hline DI- & $2800 \pm 500$ & $1500 \pm 500$ & $3900 \pm 1700$ \\
\hline TRI- & $66 \pm 27$ & $36 \pm 11$ & $103 \pm 56$ \\
\hline TETRA- & $7 \pm 2$ & $7 \pm 1$ & $6 \pm 4$ \\
\hline PENTA- & $2 \pm 1$ & $10 \pm 3$ & nd \\
\hline HEXA- & $40 \pm 30$ & $22 \pm 2$ & $20.0 \pm 0.4$ \\
\hline Total & 38845 & 16918 & 31722 \\
\hline \multicolumn{4}{|c|}{ Chlorophenols ( $\mu \mathrm{g} / \mathrm{kg}$ dry basis) } \\
\hline MONO- & $1850 \pm 520$ & $1550 \pm 430$ & $1350 \pm 590$ \\
\hline DI- & $750 \pm 440$ & $440 \pm 150$ & $780 \pm 290$ \\
\hline TRI- & $43 \pm 24$ & $25 \pm 4$ & $15 \pm 7$ \\
\hline TETRA- & $2.3 \pm 0.4$ & $14.9 \pm 2.6$ & $1.7 \pm 2.1$ \\
\hline PENTA- & $26 \pm 11$ & $19 \pm 3$ & $17 \pm 3$ \\
\hline Total & 2676 & 2043 & 2156 \\
\hline
\end{tabular}


Table 6. TEQ concentrations of PCDD/Fs and dl-PCBs ( $\mu \mathrm{g}$ WHO-TEQ $\mathrm{kg}^{-1}$ dry

\begin{tabular}{|c|c|c|c|c|}
\hline \multirow[b]{2}{*}{ COMPOUND } & \multicolumn{4}{|c|}{ ng WHO-TEQ/kg dry sample } \\
\hline & $\begin{array}{c}\text { M0 (wood/PVC }) \\
(n=2)\end{array}$ & $\begin{array}{c}\text { M1(wood/PVC/PUF }) \\
(n=2)\end{array}$ & $\begin{array}{c}\text { M2 } \\
(\operatorname{wood} / \mathrm{PVC} / \mathrm{PUF} \\
\text { gases })(\mathrm{n}=2)\end{array}$ & LOB* \\
\hline 2378-TCDF & $0.7 \pm 0.9$ & $0.2 \pm 0.3$ & nd & 0.006 \\
\hline 12378-PeCDF & $0.9 \pm 1.3$ & $0.2 \pm 0.3$ & $0.05 \pm 0.08$ & 0.001 \\
\hline 23478-PeCDF & $118 \pm 49$ & $24 \pm 12$ & nd & 0.01 \\
\hline 123478-HxCDF & $52 \pm 34$ & $5.6 \pm 2.0$ & nd & 0.008 \\
\hline 123678-HxCDF & $74 \pm 47$ & $10.0 \pm 0.4$ & nd & 0.008 \\
\hline 234678-HxCDF & $146 \pm 66$ & $19 \pm 3$ & $1.2 \pm 1.7$ & 0.009 \\
\hline 123789-HxCDF & $112 \pm 82$ & $16 \pm 1$ & nd & 0.02 \\
\hline 1234678-HpCDF & $51 \pm 32$ & $4.9 \pm 0.3$ & $0.9 \pm 1.2$ & 0.001 \\
\hline 1234789-HpCDF & $13 \pm 10$ & $0.6 \pm 0.8$ & nd & 0.002 \\
\hline OCDF & $0.7 \pm 0.5$ & $0.05 \pm 0.07$ & $0.03 \pm 0.05$ & 0.0001 \\
\hline 2378-TCDD & nd & nd & nd & 0.06 \\
\hline 12378-PeCDD & nd & $0.6 \pm 0.8$ & nd & 0.1 \\
\hline 123478-HxCDD & $0.2 \pm 0.3$ & nd & nd & 0.03 \\
\hline 123678-HxCDD & $2.2 \pm 3.0$ & $0.2 \pm 0.3$ & nd & 0.03 \\
\hline 123789-HxCDD & $0.1 \pm 0.2$ & nd & nd & 0.1 \\
\hline 1234678-HpCDD & $1.1 \pm 1.6$ & $0.2 \pm 0.3$ & nd & 0.01 \\
\hline OCDD & nd & nd & nd & 0.001 \\
\hline Total PCDFs & 569.3 & 81.7 & 2.1 & \\
\hline Total PCDDs & 3.6 & 0.9 & nd & \\
\hline Total PCDD/Fs & 572.9 & 82.6 & 2.1 & \\
\hline Reduct. Rate (\%) & - & 85.7 & 99.6 & \\
\hline PCB-77 & $3.2 \cdot 10^{-3} \pm 7.9 \cdot 10^{-4}$ & $5.9 \cdot 10^{-4} \pm 8.3 \cdot 10^{-4}$ & $2.0 \cdot 10^{-4} \pm 2.9 \cdot 10^{-4}$ & $6.5 \cdot 10^{-6}$ \\
\hline PCB-81 & nd & $7.1 \cdot 10^{-4} \pm 1.0 \cdot 10^{-3}$ & nd & $2.1 \cdot 10^{-5}$ \\
\hline PCB-126 & $9.7 \pm 4.0$ & $1.6 \pm 0.8$ & nd & 4. $7 \cdot 10^{-3}$ \\
\hline PCB-169 & nd & $0.2 \pm 0.1$ & nd & 2. $0 \cdot 10^{-3}$ \\
\hline PCB-105 & $6.9 \cdot 10^{-4} \pm 1.5 \cdot 10^{-4}$ & nd & nd & $1.8 \cdot 10^{-5}$ \\
\hline PCB-114 & nd & nd & nd & $1.5 \cdot 10^{-5}$ \\
\hline PCB-118 & nd & $5.3 \cdot 10^{-5} \pm 7.4 \cdot 10^{-5}$ & $1.5 \cdot 10^{-4} \pm 2.1 \cdot 10^{-4}$ & $2.4 \cdot 10^{-5}$ \\
\hline PCB-123 & nd & $6.6 \cdot 10^{-5} \pm 9.4 \cdot 10^{-5}$ & $1.8 \cdot 10^{-4} \pm 2.6 \cdot 10^{-4}$ & $4.3 \cdot 10^{-6}$ \\
\hline PCB-156 & $2.2 \cdot 10^{-3} \pm 1.1 \cdot 10^{-3}$ & $6.7 \cdot 10^{-5} \pm 9.5 \cdot 10^{-5}$ & nd & $7.9 \cdot 10^{-6}$ \\
\hline PCB-157 & $6.8 \cdot 10^{-4} \pm 9.6 \cdot 10^{-4}$ & $8.2 \cdot 10^{-5} \pm 1.2 \cdot 10^{-4}$ & nd & $8.4 \cdot 10^{-6}$ \\
\hline PCB-167 & $3.4 \cdot 10^{-4} \pm 4.8 \cdot 10^{-4}$ & $1.3 \cdot 10^{-5} \pm 1.8 \cdot 10^{-5}$ & $1.0 \cdot 10^{-5} \pm 1.49 \cdot 10^{-5}$ & $1.2 \cdot 10^{-5}$ \\
\hline PCB-189 & $3.0 \cdot 10^{-3} \pm 2.1 \cdot 10^{-3}$ & nd & nd & $5.9 \cdot 10^{-6}$ \\
\hline Total PCBs & 9.71 & 1.83 & $5.5 \cdot 10^{-4}$ & \\
\hline
\end{tabular}


* LOB: Limit of Blank.

506 nd: result below LOB.

507 


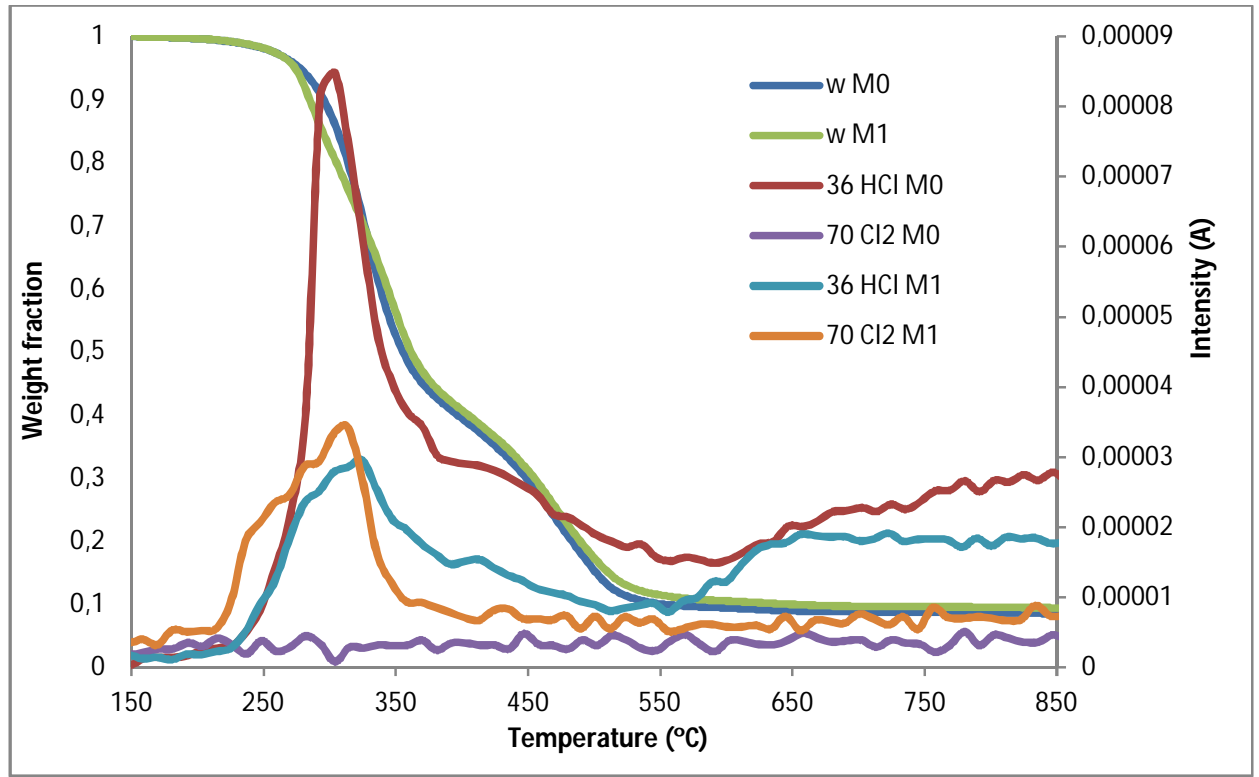

509 Figure 1. Intensities of ions corresponding to $\mathrm{HCl}$ and $\mathrm{Cl}_{2}$ in TG-MS runs for $\mathrm{M} 0$ and M1 combustion.

511 